\title{
PKM KELOMPOK PEREMPUAN USIA REPRODUKTIF BERISIKO KANKER PAYUDARA DI KELURAHAN PATRANG DAN KELURAHAN KEBONSARI KABUPATEN JEMBER PROPINSI JAWA TIMUR
}

\author{
Luh Titi Handayani $^{\# 1}$, M. Ali Hamid ${ }^{* 2}$, Hendra Kurniawan ${ }^{\# 3}$ \\ ${ }^{\# 1 * 2 \# 3}$ Jurusan Keperawatan, Universitas Muhammadiyah Jember \\ Jl. Karimata 49 Jember \\ ${ }^{1}$ luhtiti@unmuhjember.ac.id \\ ${ }^{2}$ holysfansegmail.com \\ ${ }^{3}$ hk. haryonodgmail.com
}

\begin{abstract}
Abstrak
Penyakit kanker salah satu penyebab kematian utama di seluruh dunia. Prevalensi kanker payudara di Indonesia tertinggi terdapat di Provinsi Jawa Timur dan Jawa Tengah. Kanker payudara dapat menyerang semua tingkat usia dan meningkat setelah menopause. Deteksi dini kanker payudara dapat dilakukan dengan cara pemeriksaan payudara sendiri (sadari) dan pemeriksaan payudara klinis (sadanis). Deteksi dini dapat dilakukan mandiri pada periode tertentu sesuai dengan siklus hormonal. Hasil survey pada mitra disapatkan bahwa banyak yang tidak memahami tentang tanda dan gejala, pemeriksaan sendiri (sadari), faktor resiko dan penyebab serta penatalaksanaan. Tujuan dari kegiatan ini mengidentifikasi kemampuan kader dalam melakukan pendampingan pemeriksaan sadari. Metode dalam kajian ini menggunakan metode referensi dan survey lapangan kepada perempuan usia 18 - 60 tahun sejumlah 30 responden. Demonstrasi deteksi dini sadari oleh kader dan pemeriksaan sadanis (Ultra Sono Graphy (USG)) dilakukan. Analisis data dilakukan secara deskriptif terhadap variabel usia, status menikah, jumlah anak, riwayat hormonal, dan pola hidup sehat dan hasil USG. Hasil wawancara dengan responden bahwa kader melakukan deteksi dini dengan pemeriksaan sadari dengan baik (90\%). Hasil pemeriksaan sadari oleh kader didapatkan dua responden ada benjolan pada payudara. Hasil pemeriksaan sadanis (USG) $\mathbf{1 0 0 \%}$ tidak didapatkan tanda keganasan terhadap responden. Pemberdayaan masyarakat bidang kesehatan dalam upaya deteksi dini kanker payudara dapat dilakukan dengan baik oleh kader. Peran kader dalam kesehatan sebagai penyambung informasi kesehatan secara langsung pada kelompok masyarakat terkecil yaitu keluarga dan individu dalam upaya meningkatkan status kesehatan masyarakat.
\end{abstract}

Kata Kunci- peran kader, screening kanker payudara

\section{PENDAHULUAN}

Kanker payudara adalah tumor ganas pada jaringan payudara. Jaringan payudara terdiri dari kelenjar susu, saluran kelenjar, dan jaringan penunjang payudara. Kanker payudara terjadi karena adanya kerusakan pada gen yang mengatur pertumbuhan dan diferensiasi sehingga sel itu tumbuh dan berkembangbiak tanpa dapat dikendalikan. Penyebaran kanker payudara terjadi melalui pembuluh getah bening dan tumbuh di kelenjar getah bening, sehingga kelenjar getah bening aksila ataupun supraklavikula membesar, kemudia melalui pembuluh darah kanker menyebar ke organ lain seperti paru-paru, hati, dan otak (Rasjidi, 2009).

Insiden kanker di Indonesia masih belum diketahui secara pasti karena belum ada registrasi kanker berbasis populasi yang dilaksanakan. Berdasarkan estimasi Globocan, International Agency for Research on Cancer (IARC) tahun 2012, kanker payudara adalah kanker dengan persentase kasus baru tertinggi $(43,3 \%)$ dan persentase kematian tertinggi $(12,9 \%)$ pada perempuan di dunia. Berdasarkan data Riset Kesehatan Dasar tahun 2013, prevalensi kanker payudara di Indonesia mencapai 0,5 per 1000 perempuan (Kemenkes RI, 2014).

Berdasarkan data dari Sistem Informasi Rumah Sakit tahun 2010, kanker payudara adalah jenis kanker tertinggi pada pasien rawat jalan maupun rawat inap mencapai 12.014 orang $(28,7 \%)$. Berdasarkan data Subdit Kanker Direktorat Pengendalian Penyakit Tidak Menular (PPTM) Kemenkes RI, jumlah perempuan seluruh Indonesia umur 30-50 tahun adalah 36.761.000. Sejak tahun 2007-2013 deteksi dini yang telah dilakukan oleh perempuan sebanyak 644.951 orang $(1,75 \%)$ dengan penemuan suspek benjolan (tumor) payudara 1.682 orang (2,6 per 1000 penduduk) (Kemenkes RI, 2014).

Beberapa risiko yang meningkatkan kejadian kanker payudara, antara lain usia, obesitas, gaya hidup, terapi hormonal termasuk penggunaan alat kontrasepsi hormonal jangka panjang, tidak menyusui, genetic, dll. Bertambahnya usia merupakan salah satu faktor risiko paling kuat timbulnya kanker payudara. Meskipun kanker payudara dapat terjadi pada wanita muda,secara umum merupakan penyakit penuaan. Seorang wanita 
berusia 30-an risikonya kira-kira 1 dalam 250, sedangkan untuk wanita pada usia 70-an nya,adalah sekitar 1 dari 30. Sebagian besar kanker payudara yang didiagnosis adalah setelah menopause dan sekitar $75 \%$ dari kasus kanker payudara terjadi setelah 50 tahun (National Breast and Ovarian Cancer Centre, 2009). Kanker payudara dapat timbul seiring dengan meningkatnya usia. Sekitar 8 dari 10 kasus kanker payudara terjadi pada wanita di atas usia 50 tahun dan kondisi ini paling banyak menyerang para wanita yang telah mengalami menopause. Di Inggris, wanita yang berusia sekitar 50 sampai 70 tahun, melakukan skrining setiap 3 tahun sekali yang dilakukan oleh NHS Breast Screening Programme (Anonymus, 2014).

Mitra merupakan kelompok lansia yang usianya lebih dari 50 tahun dengan berbagai macam kondisi yang merupakan punya faktor risiko terkena kanker payudara. Berdasarkan hasil penelitian menunjukkan bahwa usia di atas 50 tahun mempunyai risiko yang paling kuat timbulnya kanker payudara. Hasil survey kepada mitra juga menunjukkan bahwa mitra kurang paham tentang kanker payudara, dan cara pemeriksaan kanker payudara yang dilakukan secara mandiri. Beberapa kejadian yang lazim muncul terkait dengan kanker payudara di mitra adalah ketidaktahuan mitra tentang tanda dan gejala awal kanker payudara, ketidaktahuan mitra dalam melakukan pemeriksaan dini secara mandiri tanda dan gejala kanker payudara. Sehingga yang dapat terjadi adalah keterlambatan penangan dan pengobatan kanker payudara.

Studi Pendahuluan yang dilakukan adalah melalui kegiatan rutin RT dan didapatkan sebagian besar ibu adalah usia reproduktif. Mitra I dan II adalah sekelompok perempuan dengan sebagian besar usia reproduktif 18-60 tahun. Dengan umur yang bervariasi dari usia muda sampai lansia pada perempuan tidak jauh dengan permasalahn reproduksi dimana hal ini berhubungan dengan sistem hormonal. Sehingga siapapun itu perempuan mempunyai rsiko terkena gangguan dengan sistem reproduksi. Tentunya hal ini berhubungan dengan faktor - faktor lain yang menjadi faktor predsiposisi misalnya status paritas (melahirkan), penggunaan obat hormonal (KB), Bertambahnya usia, obesitas, gaya hidup, terapi hormonal termasuk penggunaan alat kontrasepsi hormonal jangka panjang, tidak menyusui, genetic, dll. Hasil survey kepada mitra juga menunjukkan bahwa 90\% mitra kurang paham tentang kanker payudara, dan $100 \%$ tidak memahami cara pemeriksaan kanker payudara yang dilakukan secara mandiri. Beberapa kejadian yang lazim muncul terkait dengan kanker payudara di mitra adalah ketidaktahuan mitra tentang tanda dan gejala awal kanker payudara, ketidaktahuan mitra dalam melakukan pemeriksaan dini secara mandiri tanda dan gejala kanker payudara. Sehingga yang dapat terjadi adalah keterlambatan penanganan dan pengobatan kanker payudara. Keterlambatan penanganan yang dapat terjadi pada mitra akan semakin meningkatkan risiko tinggi terjadinya kematian akibat kanker payudara.

Berdasarkan uraian diatas datap ditarik kesimpulan bahwa masalah yang terjadi pada mitra adalah : 1) Rendahnya pengetahuan Mitra tentang penyakit kanker payudara, 2) Ketidakmampuan mengenal tanda dan gejala, 3) Ketidaktahuan pemeriksaan payudara sendiri, 4) Ketidaktahuan mengenal faktor resiko, 5) Rendahnya kesadaran Mitra ber PHBS (perilaku hidup bersih dan sehat), 6) Ketidaktahuan mencegah kanker payudara, 7) Belum pernah melakukan screening pemeriksaan penunjang.

Melihat fakta yang ada pada mitra maka perlu segera diberikan solusi guna mencegah terjadinya kanker payudara pada tahap yang lebih lanjut. Karena, kejadian kanker payudara sebagain besar diketahui setelah pada stadium lanjut dan sudah mengalami keterlambatan untuk dilakukan pengobatan. Pemberian pendidikan kesehatan, memberikan pelatihan cara melakukan pemeriksaan mandiri tanda dan gejala kanker payudara diharapkan dapat memberikan nilai positif bagi mitra pada khususnya dan mencegah keterlambatan pengobatan kanker payudara pada umumnya. Selain memberikan pendidikan kesehatan kepada mitra, guna memberikan wadah agar pelaksanaan deteksi dini penyakit-penyakit yang lazim terjadi pada lansia wanita, khususnya pada kejadian kanker payudara, maka perlu dibentuk kader kesehatan yang selalu melakukan tindak lanjut kegiatan ini. Dibentuknya wadah ini diharapkan dapat memfasilitasi kelompok lansia yang ada pada mitra dalam permasalahan kesehatan yang dihadapinya.

\section{TARGET DAN LUARAN}

Hasil identifikasi, permasalahan yang dihadapi mitra adalah rendahnya pengetahuan mitra tentang kanker payudara, penyebab kanker payudara, risiko timbulnya kanker payudara pada wanita, tanda dan gejala dini timbulnya kanker payudara, pencegahan kanker payudara, serta belum memahaminya mitra cara melakukan pemeriksaan secara mandiri dalam mengenali tanda dan gejala kanker payudara. Melihat permasalahan di atas, maka pendekatan yang dapat dilakukan guna menyelesaikan permasalahan kesehatan yang ada di mitra adalah: 1) membentuk Kader Deteksi Dini kanker Payudara, 2) pelatihan pemeriksaan secara oleh kader, 3) penyuluhan kesehatan, 4) pemeriksaan klinis (sadanis). 


\section{METODE PELAKSANAAN}

Metode yang dilakukan :

1) Membentuk kader deteksi dini kanker payudara Pembentukan kader mandiri pada mitra I dan II melalui pendekatan tokoh perempuan melalui ibu RW, RT dan ketua PKK untuk menentukanan namanama kader. Dalam pembentukan kader juga diberikan tentang tugas tupoksi kader. Pembentukan kader bersifat mandiri dan tanpa ada finansial yang didaptkan kader karena bersifat sukarela dalam upaya meningkatkan derajad kesehatan terutama dalam sistem reproduksi pencegahan kanker payudara melalui deteksi dini.

2) Pelatihan pemeriksaan secara oleh kader Pelatihan diberikan oleh tenaga kesehatan kepada kader yang sudah dibentuk. Pelatihan yang diberikan meliputi pengertian, pengenalan tanda dan gejala, waktu pemeriksaan sadari dan sadanis, teknik pemeriksaan sadari.

3) Penyuluhan kesehatan

Penyuluhan kesehatan diberikan oleh tim kesehatan kepada semua peserta yang hadir baik pada mitra I dan II sebanyak 30 orang. Penyuluhan kesehatan diberikan dengan materi yang sama dengan yang diberikan kepada kader. Diwaktu yang sama kader juga membentuk kelompok kecil. Di setiap satu mitra ada 4 kader dan setiap kader memberikan teknik sadari kepada 3-4 anggota.

4) pemeriksaan klinis (sadanis).

Untuk menunjang pemeriksaan sadari, maka dilakukan pemeriksaan sadanis dengan pemeriksaan USG payudara kepada 8 orang sebagai sampel dari kelompok mitra I dan II dikarenakan keterbatasan dana yang dialokasikan.

\section{IV.HASIL DAN PEMBAHASAN}

Pelaksanaan progam pengbadian dengan pendanaan Menristekdikti tahun 2018 dilaksanakan pada bulan Juli - September 2018 baik pada mitra I dan II.

1) Membentuk kader deteksi dini kanker payudara.

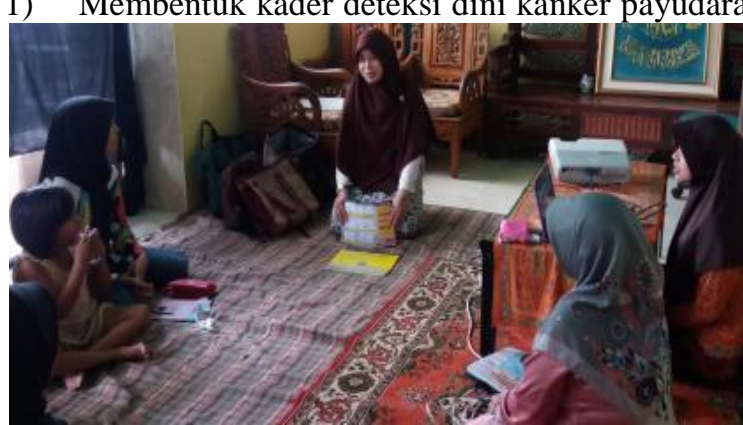

Gambar 1. Membentuk kader deteksi dini

Kegiatan pertama dilakukan dengan mengundang toga dan toma perempuan termasuk ketua PKK untuk memberikan nama-nama anggota yang mempunyai kemampuan dan sukarela menjadi kader. Masing - masing mitra mempunyai 4 (empat) kader yang dimasukkan dalam tupoksi menjadi kader. Dalam tupoksi kader yang dibuat tercantum tentang tugas - tugas kader dalam melakukan deteksi dini kanker payudara. Hal terpenting dititikberatkan dalam penyusunan tupoksi ini adalah keberlanjutan dalam kegiatan mandiri setelah program dari menristekdikti selesai. Melalui pendekatan kepada tokoh diharapkan mampu menjadi pengendali kegiatan mengingat pemeriksaan rutin ini dalam mewujudkan derajad kesehatan dan menurunkan angka kematian perempuan tanpa harus mengeluarkan finansial dan hanya diperlukan kemauan dan ketelatenan dalam melakukan pemeriksaan secara mandiri pada setiap bulannya.

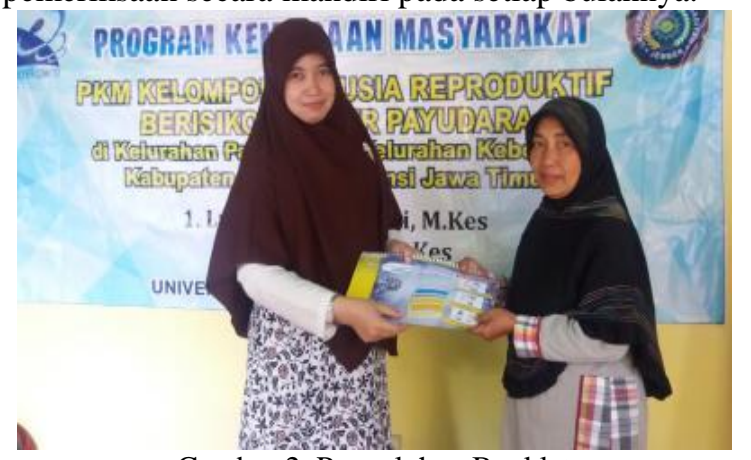

Gambar 2. Penyuluhan Booklet

Dalam kegiatan pembentukan kader juga diberikan penyerahan seperangkat media untuk penyuluhan berupa booklet, leaflet dan manikin payudara yang diberikan sebagai hibah kepada mitra.

2) Pelatihan pemeriksaan secara oleh kader

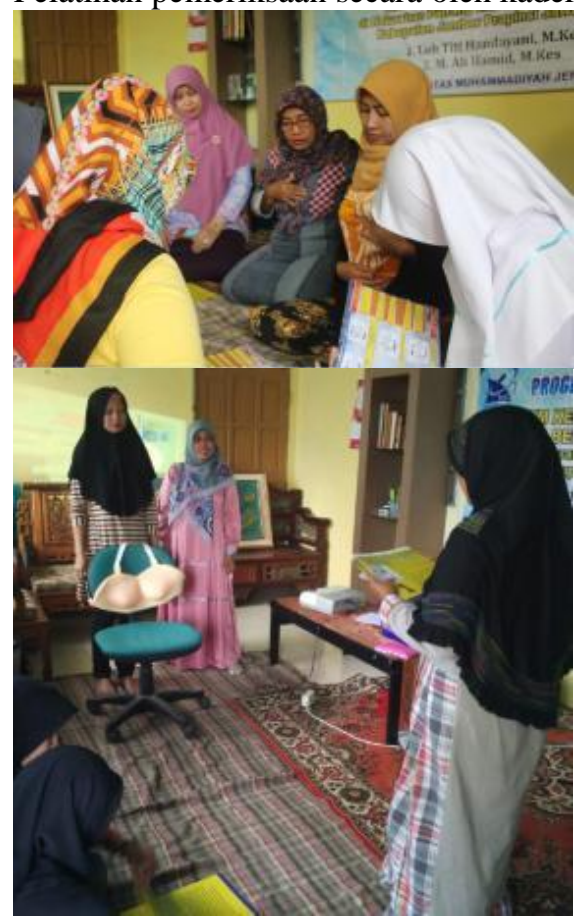

Gambar 3. Pelatihan pemeriksaan secara oleh kader 
Pelatihan pemeriksaan mandiri oleh kader diberikan oleh tenaga kesehatan dengan topik yang sama dengan tupoksi kader. Pelatihan dilakukan dua kali pada setiap mitra dengan harapan bahwa kader dapat melaksanakan dengan benar dalam melakukan pendampingan terhadap pemeriksaan sadari oleh peserta. Hasil yang didapatkan melalui pendampingan tenaga kesehatan bahwa kader dapat melakukan dengan benar dan percaya diri. Peran kader sebagai ujung tombak pelayanan dasar dari pelayanan kesetahan diharapkan dapat menjangkau sararan dengan tepat. Diharapkan dengan peran kader dapat berjalan lanjut meski proses pengabdian yang didanai sudah berakhir. Kader adalah tenaga sukarela dari kelompok masyarakat dalam membantu meningkatkan derajad kesehatan masyarakat.

3) Penyuluhan kesehatan

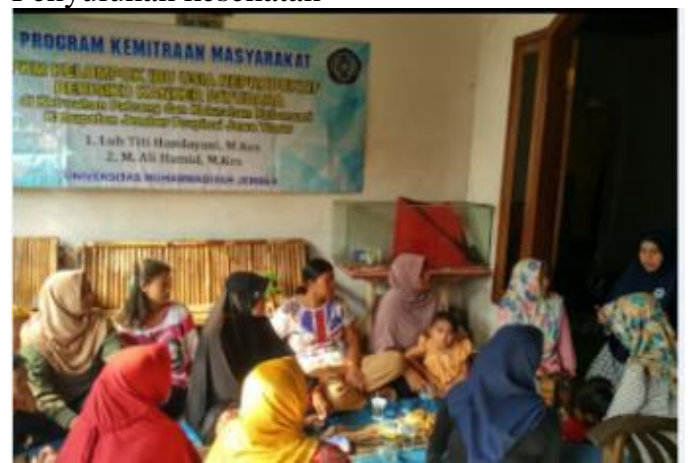

Gambar 4. Penyuluhan kesehatan

Faktor perilaku dan pola makan memiliki peran penting terhadap timbulnya kanker. Kanker payudara disebut sebagai penyebab terbesar kematian wanita yang disusul oleh kanker leher rahim. Penyuluhan merupakan sebuah metode penyampaian informasi. Selain diberikan dalam bentuk ceramah, demonstrasi, dan praktik, responden juga diberikan media leaflet di dalam pelaksanaan kegiatan. Pengetahuan tentang kesehatan organ reproduksi terlebih pada wanita yang memiliki sistem reproduksi yang sangat rentan sekali terhadap bahaya terkontaminasinya kuman dan bibit penyakit yang mengancam kehidupan organ intim wanita. Setelah mengikuti kegiatan penyuluhan ini, tidak ada salahnya untuk sharing dengan para suami agar para suami juga tahu pentingnya menjaga kesehatan wanita terutama pencegahan terhadap kanker payudara. Diharapkan dengan deteksi dini ini, apabila hasil tesnya ternyata positif maka dapat diambil langkah -langkah yang tepat dalam rangka mencegah. pentingnya peningkatan gaya hidup sehat sebagaimana yang diusung oleh Dinkes KBB yaitu "Gaya Hidup Cerdik" (Cek kesehatan secara berkala, Enyahkan asap rokok, Rajin aktifitas fisik, Diet sehat dengan gizi seimbang, Istirahat yang cukup dan Kelola Stress).
4) Pemeriksaan klinis (sadanis).

Setelah peserta dari mitra bersama kader melakukan pemriksaan sadari, maka diambil delapan orang sebagai sampel untuk dilakukan pemeriksaan sadanis (USG payudara) yang dipilih dari rentang usia 18 60 tahun. Tidak semua anggota mitra dipilih semua diperiksa sadanis dikarenakan keterbatasan alokasi dana penelitian. Selain alokasi dana adalah penolakan responden untuk diperiksa dikarenakan takut dengan melihat hasil pemeriksaan. Hasil dari semua sampel yang diperiksa semua hasil menunjukkan hasil USG payudara dalanm batas normal.

\section{KESIMPULAN}

Kegiatan Program Kemitraan Masyarakat ini memberikan kontribusi yang positif kepada masyarakat sasaran (Mitra) antara lain : 1) meningkatkan pengetahuan dan pemahaman Mitra tentang screening payudara dalam mencegah kanker payudara, 2) meningkatkan pemahaman mitra tentang pencegahan kanker payudara melalui deteksi dini dengan pemeriksaan sadari dan sadanis, 3) meningkatkan peran serta masyarakat dengan melalui kader yang dibentuk dalam membantu meningkatkan derajad kesehatan perempuan. Rencana tahapan berikutnya kegiatan PKM ini adalah: 1) Melakukan evaluasi program kegiatan yang dilakukan secara terencana dan berkala.

\section{UCAPAN TERIMAKASIH}

Direktorat Riset dan Pengabdian Kepada Masyarakat. Kementrerian Riset dan Teknologi Pendidikan Tinggi yang telah membiayai program kegiatan ini.

\section{DAFTAR PUSTAKA}

[1] American Cancer Society. 2007. How Many People Have Breast Cancer. http;//www.cancer.org. Diakses tanggal 3 Mei 2016.

[2] Anonymus (2014). 15 Penyebab Kanker Payudara Yang Perlu Diwaspadai. http://faktakanker.com/. Diakses pada 10 April 2016

[3] Globocan, International Agency for Research on Cancer (IARC). 2002. http;//www.Globocan.go.id. Diakses tanggal 10 April 2016.

[4] Kementerian Kesehatan RI. 2015. Cegah Kanker dengan Menerapkan Perilaku Cerdik. Jakarta: Pusat data dan Informasi.

[5] Kementerian Kesehatan RI, 2015. Situasi Penyakit Kanker. Jakarta: Pusat Data dan Informasi.

[6] Kementerian Kesehatan RI, 2014. Kebijakan dan Strategi Nasional Pencegahan dan Penanggulangan Penyakit Tidak Menular. Jakarta: KEMENKES RI

[7] National Breast and Ovarian Cancer Centre (2009). https://www.health.gov.au/ diakses 10 April 2016 